\title{
NEW SURVEY ANALYZES BIOTECH FINANCES
}

SAN FRANCISCO-As biotechnology companies grow, more of their income is generated from product sales and less from interest, and the percentage of total spending devoted to R\&D decreases. Regardless of company size, however, the growth in revenues usually exceeds the growth in expenses, implying that many of these firms are on the road toward profitability. Large firms spend more dollars on R\&D than small ones, but the percent of employees involved in $\mathrm{R} \& \mathrm{D}$ remains fairly stable at $33 \%$ for small firms and $30 \%$ for large. Interestingly, it is the mid-sized firms (defined as having 51-135 employees), who devote the largest portion of their staffs $(48 \%)$ to R\&D.

These findings and more come from a soon-to-be-released survey of U.S. public and private biotechnology firms performed by Arthur Young's High Technology Group. According to Steven Burrill, chairman of the group, the survey will be updated annually, so "in future years the changes should tell us a lot about what is going on." For now, this initial effort by the international accounting and consulting firm provides a snapshot of important financial ratios of the biotechnology industry, useful for companies trying to determine quantitatively their performance.

The survey finds that $36 \%$ of public companies emphasize diagnostics, $34 \%$ stress therapeutics, while $18 \%$ are suppliers and only $6 \%$ focus on plant and animal healthcare. For private companies, however, a smaller percentage is involved in diagnostics $(20 \%)$ and therapeutics $(12 \%)$, while plant and animal healthcare $(27 \%)$ and suppliers $(22 \%)$ dominate. This could indicate a shift on the part of younger firms into new markets.

For the public companies, the way capital is raised varies with the size of the firm. For all, the public equity markets are the largest source: $27 \%$ of funds for small firms, $42 \%$ for mid-sized companies, and $30 \%$ for large. But the big companies make greater use of $\mathrm{R} \& \mathrm{D}$ partnerships (16\% as compared to $9 \%$ for small and $6 \%$ for medium) and bank borrowings ( $13 \%$ as compared to $3 \%$ for small and $1 \%$ for mid-sized). The smaller companies, on the other hand, take greater advantage of private equity placements.

One particularly interesting statistic the Arthur Young group analyzed is the "research and development survival rate," which projects the number of years a company's current $R \& D$ spending rate can be supported by its cash and short-term investments. This $\mathrm{R} \& \mathrm{D}$ burn rate averages out to 3.6 years for small companies, 3.4 years for mid-sized companies, and 2.7 years for large. When capital expenditures are added to the $\mathrm{R} \& \mathrm{D}$ expenses, the ratios decrease to 2.6 years for small companies, 2.2 for mid-sized firms, and only 1.4 years for large. Burrill concludes that "younger companies have done a spectacular job of accumulating capital," while the more mature companies may feel more confident about their future abilities to tap capital markets or cut spending.

\section{-Arthur Klausner}

Copies of the survey will be available later this month by calling the Arthur Young High Technology Group in San Francisco at 1-8003HI-TECH.

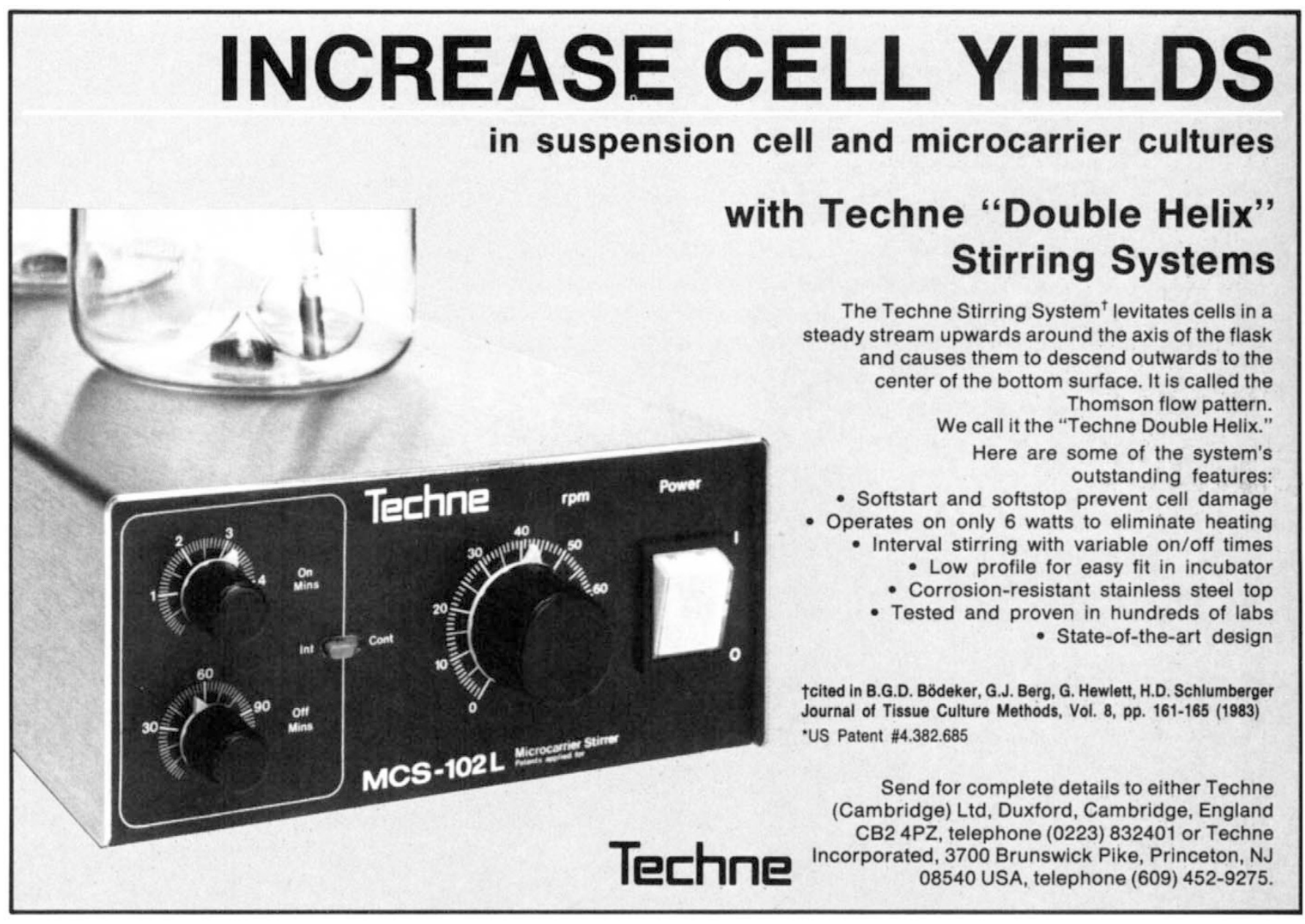

